\title{
Cardiovascular Risk Factors Among Patients Infected with COVID-19 in Saudi Arabia
}

\author{
Mashael K Alshaikh (D) \\ Hadil Alotair (D) ${ }^{2}$ \\ Farrah Alnajjar (D) ${ }^{3}$ \\ Hanaa Sharaf ${ }^{4}$ \\ Bader Alhafi (iD ${ }^{5}$ \\ Lolwah Alashgar ${ }^{2}$ \\ Mohammed Aljuaid (D) ${ }^{6}$ \\ 'Department of Pharmacy Services, King \\ Saud University Medical City, Riyadh, \\ Saudi Arabia; ${ }^{2}$ Department of Medicine, \\ King Saud University Medical City. King \\ Saud University, Riyadh, Saudi Arabia; \\ ${ }^{3}$ Yanbu General Hospital, Ministry of \\ Health, Riyadh, Saudi Arabia; \\ ${ }^{4}$ Department of Cytogenetics \\ Laboratory, Ministry of Health, Riyadh, \\ Saudi Arabia; ${ }^{5}$ Department of \\ Agricultural Extension and Rural Society, \\ King Saud University, Riyadh, Saudi \\ Arabia; ${ }^{6}$ Department of Health \\ Administration, College of Business \\ Administration, King Saud University, \\ Riyadh, Saudi Arabia
}

Background: Coronavirus disease (COVID-19) is a global pandemic with more than 60 million cases worldwide and over 1.5 million deaths by March 2021. Its outbreak has caused a huge burden on healthcare systems all over the world. Several studies in the medical literature have suggested that patients with underlying cardiovascular disease (CVD) are at higher risk for developing severe symptoms, poor prognosis, and high mortality rates. The aim of this study was to assess the prevalence of CVD risk factors among COVID-19 patients based on the Framingham risk score (FRS), and to evaluate the association of CVD risk factors with clinical outcomes.

Patients and Methods: In this retrospective cross-sectional study, we identified 264 confirmed cases with COVID-19 at King Saud University Medical City in Riyadh, Saudi Arabia. Patients aged 18-80 years were included, and their electronic records were reviewed. They were classified into low, intermediate, and high risk of CVD according to FRS classification.

Results: Two-hundred-six patients (67\% male) were included in this study. The mean age was $55.3 \pm 15.1$ years. Most patients had comorbidities: the most common were hypertension $(48.1 \%)$, diabetes $(45.1 \%)$, and ischemic heart disease $(11.2 \%)$. More than half required intensive care admission, and $58(28.2 \%)$ patients died. Pneumonia was the most frequently observed complication ( $85 \%)$, followed by mechanical ventilation $(28.3 \%)$ and acute kidney injury (27.7\%). Age, male gender, hypertension, and diabetes mellitus showed significant differences between FRS categories, and were associated with intermediate and high-risk groups of FRS $(\mathrm{p}<0.05)$. Pneumonia and length of stay were associated with the Intermediate risk group of FRS.

Conclusion: Cardiovascular disease risk factors are prevalent in Saudi patients infected with COVID-19. FRS could be a useful tool to identify CVD risk factors among COVID-19 patients and predict a complicated course.

Keywords: Framingham risk score FRS, COVID-19, cardiovascular risk factors, Saudi Arabia

\section{Introduction}

Coronavirus disease (COVID-19) is an infectious disease caused by the newly discovered SARS-COV 2 virus. By March 2021, COVID-19 has affected more than 60 million persons globally, with over 1.5 million deaths. ${ }^{1}$ This has caused a huge burden on healthcare systems all over the world. Nationally, in the Kingdom of Saudi Arabia (KSA), there have been 357,623 confirmed cases of COVID-19, with more than 5000 deaths, according to the Saudi Ministry of Health and the Saudi Centre of Disease Prevention and Control (report on December 1st 2020). ${ }^{2}$
Correspondence: Mohammed Aljuaid Department of Health Administration, College of Business Administration, King Saud University, P.O. Box 7115, Riyadh,

I I45I, Saudi Arabia

Tel +966 I| 4674305

Fax +966 II 4693964

Email maljuaid@ksu.edu.sa 
A large analysis was conducted on COVID-19 patients by the Chinese Centre for Disease Control and Prevention, suggesting that patients with a previous history or underlying cardiovascular disease (CVD) are at higher risk for developing severe symptoms and poor prognosis. ${ }^{3}$ High mortality rates were associated with CVD (10.5\%) and hypertension (HTN) $(6.0 \%)$. The overall mortality rate was $(2.3 \%){ }^{3}$ Another study by the US Department of Health and Human Services (Centers for Disease Control and Prevention) concluded that the hospitalization rate of COVID-19 patients was highest in those 65 years old and above (13.8\%), and among adult patients, $89.3 \%$ had one or more underlying conditions; HTN (49.7\%) and CVD $(27.8 \%){ }^{4}$

A meta-analysis of seven studies with a total of 6922 patients had shown that dyslipidemia is associated with severe COVID-19 infections, and suggested that patients with dyslipidemia should be monitored closely to minimize the risk of COVID-19. ${ }^{5}$ Diabetes mellitus (DM) has also been highlighted as an important predictor of poor outcome among patients with COVID-19, which is probably related to its proinflammatory state. ${ }^{6}$

Nationally, in KSA, Alsofayan et al had analyzed data of 1519 cases of COVID-19 and found $20.1 \%$ of the patients had underlying comorbidities; Hypertension in $8.8 \%$, and diabetes in $7.6 \%$ of all the cases, $71.6 \%$ of studied patients were admitted to hospitals and $4.7 \%$ required ICU treatment. ${ }^{7}$

This high prevalence of CVD among COVID-19 patients is particularly relevant to Saudi Arabia. The last survey by the Saudi General Authority of Statistics in 2018 reported that $1.21 \%$ of the Saudi population were diagnosed with CVD, 7.6\% reported a diagnosis of HTN, and $48.2 \%$ of Saudis aged 65 years or older have HTN. ${ }^{8}$ A population-based study conducted in Riyadh City to assess the risk of CVD using Framingham risk scores (FRS) found that a significant percentage of the general Saudi population have intermediate-to-high scores (FRS $\geq 10) .{ }^{9-11}$ This high prevalence of CVD in KSA may predispose Saudis to an even higher risk of COVID-19 complications as patients with CVD are more vulnerable to COVID-19 infection, and the infection itself might exacerbate their underlying CVD condition and lead to death. ${ }^{12}$ This is also true for another species of the Coronavirus family, Middle East respiratory syndrome (MERS), that hit the country in 2012. ${ }^{13}$

Cardiac diseases were present in $30 \%$ and obesity in $16 \%$ of MERS cases based on a systematic review and meta-analysis of 637 MERS-CoV cases, with a mortality rate of approximately $35 \%$. The authors had suggested that these conditions down-regulate the synthesis of proinflammatory cytokines and impair the host's innate and humoral immune systems. ${ }^{14} \mathrm{~A}$ descriptive study by Assiri et al in 2013 had shown that $96 \%$ of 47 laboratory-confirmed MERS-Cov had underlying comorbidities; hypertension $34 \%$, chronic cardiac disease $28 \%$, and chronic renal disease $49 \%$. They had noticed that the case-fatality rate rose with increasing age. ${ }^{15}$ Another Saudi study found an association between severe MERS-CoV illness and patients with pre-existing health morbidity. ${ }^{16}$ This past experience with the MERS outbreak has paved the road for the Saudi authorities in controlling the spread of the current pandemic. ${ }^{13}$ Here we assess the prevalence of CVD risk factors based on FRS among a sample of COVID-19 patients admitted to hospitals in Saudi Arabia.

\section{Patients and Methods}

This study is an observational, retrospective, crosssectional study conducted between May and August 2020 at King Saud University Medical City (KSUMC) in Riyadh, Saudi Arabia. All COVID-19 cases that confirmed by real-time reverse transcription-polymerase chain reaction (RT-PCR) nasopharyngeal swab were enrolled in this study. We Included the records of alive and dead patients aged 18-80 years old. We excluded oncology patients, and pregnant or lactating women.

\section{Data Collection}

The following data were collected from patients' electronic charts:

1. Demographic data (age, sex, comorbidities).

2. Clinical presentation of COVID-19.

3. Framingham risk score "FRS" based on age, gender, systolic blood pressure, diabetes, smoking, and blood cholesterol have been calculated, Medscape website calculator:https://reference.medscape.com/ calculator/252/framingham-risk-score-2008 ${ }^{10}$

Patients were categorized based on the 10-year FRS into three groups: low risk $(<10 \%)$, intermediate risk (10-20\%) and high risk (>20\%).

4. History of smoking.

5. The baseline of all the metrics (Blood pressure, Body mass index (BMI), Glycosylated haemoglobin (HbA1C), total lipid profile values obtained during previous outpatient visits, D-dimer, Complete Blood 
Count (CBC) with differential, serum ferritin, Lactate dehydrogenase (LDH), and coagulation parameters).

6. Administered medications.

In case of missing elements in the patient history, direct contact was made with the surviving impacted patients or the families of those who died.

Outcomes to be evaluated:

1. Length of stay in hospital (including ICU admission).

2. Pneumonia

3. ARDS (Acute Respiratory Distress Syndrome) According to Berlin definition. ${ }^{17,18}$

4. Mechanical ventilation.

5. Shock

6. Acute kidney injury, defined as an abrupt (within 48 hours) reduction in kidney function based on an elevation in serum creatinine level, a reduction in urine output, the need for renal replacement therapy (dialysis), or a combination of these factors. ${ }^{19}$

7. Acute heart failure. Acute heart failure is defined as a rapid onset of new or worsening signs and symptoms of HF. ${ }^{20}$

8. In-hospital mortality.

\section{Ethical Approval}

The study was approved by the KSUMC Institutional Review Board, reference number (Ref. No. 20/0497/ IRB). This study was conducted in accordance with the Declaration of Helsinki. Patient consent to review their medical records was not required by the KSUMC Institutional Review Board due to the anonymized data collection and maintained with confidentiality.

\section{Statistical Analysis}

All statistical analyses were performed using the Statistical Package for the Social Sciences software, version 22.0 (SPSS Inc., Chicago, IL, USA). Continuous variables were presented as the means \pm standard deviations (SDs) and compared using one-way ANOVA to test the difference between variables and three groups of FRS. The categorical data were presented as numbers and percentages (\%) and compared using the Chi-square test to determine whether there are significant differences between variables and three levels of FRS. Multiple logistic regression analysis was used to examine the association between the independent risk factors and 10-year risk for cardiovascular disorders according to FRS scoring as dependent variables. All the statistical tests were considered statistically significant if having a p-value $<0.05$.

\section{Results}

\section{Baseline Patient Characteristics}

A total of 264 patients with COVID-19 were identified at King Saud University Medical City, who enrolled in this study. Fifty-eight patients were excluded due to missing data. Ultimately, 206 patients $(70 \%)$ were included in the final analysis. The baseline characteristics of COVID-19 patients are summarized in Table 1. As shown in this table, patients were classified into low, intermediate, and high risk of CVD according to FRS classification.

Eighty-six patients (41.7\%) were in the high-risk score group. Overall, the mean age for the participants was $55.3 \pm 15.1$ years, and most patients were male (67\%). Their mean BMI was $30.1 \pm 6.8 \mathrm{~kg} / \mathrm{m}^{2}$ (obese). Comorbidities were reported in most of the patients, and the most common comorbidities were hypertension (48.1\%), diabetes $(45.1 \%)$, and ischemic heart disease $(11.2 \%)$. The most common clinical symptoms during admission were shortness of breath and fever, followed by cough and diarrhoea (Table 2). In terms of treatment given, most patients received antibiotics (90.3\%) and azithromycin (58.7\%). Pneumonia (85\%) was the most frequently observed outcome complication, followed by mechanical ventilation, acute kidney injury, ARDS, and heart failure. The detailed clinical symptoms, medications, treatments, and outcomes of COVID-19 patients are shown in Table 2. Generally, the frequency and the mean of high-risk category in most of the variables were more than low-risk and intermediate-risk categories. COVID-19 patients in the highest categories of FRS had significantly higher age, male gender, more likely to have hypertension, diabetes mellitus, ischemic heart disease, cerebrovascular disease, pneumonia, and heart failure outcomes compared to those in the low or intermediate FRS categories $(p<0.05)$. More than half of the patients were admitted to the ICU units, and the length of stay in the hospital was $18.9 \pm 15.5$ days. Fifty-eight $(28.2 \%)$ of COVID-19 patients died, and most were male (81\%); 27 $(46.5 \%)$ of them were in the high-risk group with a mean age of 65 years. Similarly, acute kidney injury developed in 57 patients, $28(49 \%)$ of them were in the high-risk group. 
Table I Baseline Characteristics of COVID-19 Patients Classified by Framingham Risk Score

\begin{tabular}{|c|c|c|c|c|c|}
\hline Variables & Total $(n=206)$ & Low Risk (n =7I) & Intermediate Risk $(n=49)$ & High Risk $(n=86)$ & $P$ value \\
\hline \multicolumn{6}{|l|}{ Demographic data } \\
\hline Age $(y r)$ & $55.3 \pm 15.1$ & $41.9 \pm 10.6$ & $57.3 \pm 7.4$ & $63.8 \pm 6.7$ & $<0.00 I^{*}$ \\
\hline Sex, male & $138(67)$ & $4 \mid(57.7)$ & $30(6 \mid .2)$ & $67(77.9)$ & $0.017^{*}$ \\
\hline $\mathrm{SBP}(\mathrm{mmHg})$ & $126.1 \pm 20.8$ & $117.5 \pm 14.9$ & $125.2 \pm 17.1$ & $136.3 \pm 20.1$ & 0.536 \\
\hline $\mathrm{DBP}(\mathrm{mmHg})$ & $70.3 \pm 12.6$ & $69.3 \pm 11.4$ & $72.3 \pm 12.0$ & $72.7 \pm 16.6$ & 0.191 \\
\hline Body mass index $\left(\mathrm{kg} / \mathrm{m}^{2}\right)$ & $30.1 \pm 6.8$ & $30.1 \pm 6.9$ & $30.8 \pm 6.3$ & $30.3 \pm 6.5$ & 0.674 \\
\hline Smoking status & & & & & 0.329 \\
\hline Never & $188(91.3)$ & $64(90.1)$ & $44(89.8)$ & $80(93.0)$ & \\
\hline Former & $9(4.4)$ & $2(2.8)$ & $3(6.1)$ & $4(4.6)$ & \\
\hline Current & $9(4.4)$ & $5(7.0)$ & $2(4.1)$ & $2(2.3)$ & \\
\hline \multicolumn{6}{|l|}{ Comorbidities } \\
\hline Hypertension & $99(48.1)$ & $14(19.7)$ & $21(42.8)$ & $64(74.4)$ & $<0.00 I^{*}$ \\
\hline Diabetes mellitus & $93(45.1)$ & $13(18.3)$ & $17(34.7)$ & $63(73.2)$ & $<0.00 I^{*}$ \\
\hline Ischemic Heart Disease & $23(11.2)$ & $4(5.6)$ & $3(6.1)$ & $16(18.6)$ & $0.016 *$ \\
\hline Chronic Kidney Disease & $18(8.7)$ & $3(4.2)$ & $5(10.2)$ & $10(11.6)$ & 0.241 \\
\hline Chronic lung Disease & $17(8.3)$ & $7(9.9)$ & $3(6.1)$ & $7(8.1)$ & 0.764 \\
\hline Heart Failure & $19(9.2)$ & $3(4.2)$ & $4(8.2)$ & $12(13.9)$ & 0.106 \\
\hline Cerebrovascular accident & $15(7.3)$ & I (I.4) & $2(4.1)$ & $12(13.9)$ & $0.007^{*}$ \\
\hline
\end{tabular}

Notes: Data are presented as mean \pm standard deviation or number $(\%)$; *Statistically significant.

Abbreviations: LOS, length of stay; DBP, diastolic blood pressure; SBP, systolic blood pressure.

As presented in Table 3, a multiple logistic regression model was used to evaluate the association between risk factors characteristics of COVID-19 patients and FRS levels. The low-risk group was considered as the reference group, and 19 independent risk factor variables and outcomes associated with FRS had been identified as a consequence of their p-value at univariate analysis as well as the most risk factors for COVID-19. We found that age (OR 1.36; 95\% CI, 1.19, 1.54; $\mathrm{p}<0.000$ ), male gender (OR 0.06; 95\% CI, 0.01,0.43; $\mathrm{p}=0.005$ ), diabetes mellitus (OR 23.02; 95\% CI, 2.43, 218.28; p = 0.006), pneumonia (OR 21.19; 95\% CI, 1.41, 318.65; $\mathrm{p}=0.027$ ), and length of stay (OR 1.06; 95\% CI, 1.01, 1.12; p $=0.028$ ) were independently associated with the Intermediate risk group of FRS. However, the high-risk category of FRS was significantly associated with age (OR 1.62; $95 \% \mathrm{CI}$, $1.39,1.90 ; \mathrm{p}<0.000$ ), male gender (OR 0.004; 95\% CI, $0.00,0.05 ; \mathrm{p}<0.001$ ), hypertension (OR 10.98; 95\% CI, 1.75, 68.95; $\mathrm{p}=0.011$ ), and diabetes mellitus (OR 210.57; 95\% CI, 18.26, 2428.16; $\mathrm{p}<0.001)$.

\section{Discussion}

The present study confirms that CVD risk factors, such as age, male gender, diabetes mellitus, and hypertension, are prevalent in COVID-19 patients admitted to hospitals in KSA. To our knowledge, this is the first study in the Middle East that stratified patients with COVID-19 according to cardiovascular disease factors based on FRS and assessed the association of CVD risk factors with clinical outcomes.

During pandemics such as COVID-19, the clinical consequences and pathogenic effects can be variable and more profound in a specific population. Several studies have reported that old age is a significant risk factor for COVID-19 mortality and morbidity. ${ }^{21,22}$ In addition to older age, a large body of evidence has highlighted an increased susceptibility of patients with diabetes to infectious diseases, ${ }^{23}$ which might be attributed to malfunctioning of the immune system in diabetics. ${ }^{24,25} \mathrm{~A}$ recent systematic review and meta-analysis of 30 articles revealed an association between diabetes with poor outcomes in patients with COVID-19. ${ }^{26}$

Obesity has become a worldwide epidemic. Recent studies show that obesity might aggravate the course of COVID-19. ${ }^{21,27}$ The current study found that obesity was common among the patients with COVID-19; the mean BMI was $30.1 \pm 6.8$ regardless of their FRS risk classification. 
Table 2 Clinical Symptoms, Medications, Treatments and Outcomes of COVID-19 Patients Classified by Framingham Risk Score

\begin{tabular}{|c|c|c|c|c|c|}
\hline Variables & Total $(n=206)$ & Low Risk (n =7I) & Intermediate Risk $(n=49)$ & High Risk $(n=86)$ & $P$ value \\
\hline \multicolumn{6}{|l|}{ Clinical symptoms } \\
\hline Cough & $128(62.4)$ & $4 \mid(57.7)$ & $34(69.4)$ & $53(62.4)$ & 0.433 \\
\hline Fever & I5I (73.7) & $48(67.6)$ & $36(73.5)$ & $67(78.8)$ & 0.285 \\
\hline SOB & $154(75.9)$ & $49(70)$ & $43(87.8)$ & $62(73.8)$ & 0.071 \\
\hline Sputum & $33(16)$ & $4(5.6)$ & $13(26.5)$ & $16(18.6)$ & $0.006^{*}$ \\
\hline Hemoptysis & $3(1.5)$ & I (I.4) & $0(0)$ & $2(2.3)$ & 0.555 \\
\hline Sore Throat & $22(10.7)$ & $5(7)$ & $6(12.2)$ & II (I2.8) & 0.469 \\
\hline Neurological symptoms & $22(10.7)$ & $8(11.3)$ & $6(12.2)$ & $8(9.3)$ & 0.851 \\
\hline Diarrhea & $53(25.9)$ & $18(25.4)$ & $13(27.1)$ & $22(25.6)$ & 0.975 \\
\hline Nausea and vomiting & $50(24.3)$ & $16(22.5)$ & $9(18.4)$ & $25(29.1)$ & 0.346 \\
\hline Abdominal Pain & $19(9.2)$ & $8(11.3)$ & $2(4.1)$ & $9(10.5)$ & 0.357 \\
\hline \multicolumn{6}{|l|}{ Treatments } \\
\hline Steroids & $116(56.6)$ & $33(46.5)$ & $33(67.3)$ & $50(58.8)$ & 0.066 \\
\hline Antibiotics & $186(90.3)$ & $60(84.5)$ & $46(93.9)$ & $80(93)$ & 0.125 \\
\hline Hydroxychloroquine & $5(2.4)$ & $3(4.2)$ & $2(4.1)$ & $0(0)$ & 0.159 \\
\hline Azithromycin & $12 \mid(58.7)$ & $33(46.5)$ & $33(67.3)$ & $55(64)$ & $0.032^{*}$ \\
\hline Anti-viral & $8(3.9)$ & $4(5.6)$ & $2(4.1)$ & $2(2.3)$ & 0.564 \\
\hline \multicolumn{6}{|l|}{ Laboratory Results } \\
\hline $\mathrm{HgAlC}$ & $8.1 \pm 5.9$ & $7.1 \pm 2.7$ & $7.9 \pm 2.6$ & $9.3 \pm 9.4$ & 0.182 \\
\hline D-dimer & $3.3 \pm 4.9$ & $2.7 \pm 4.6$ & $2.0 \pm 2.0$ & $4 \pm 5.9$ & 0.407 \\
\hline HDL & $0.9 \pm 0.44$ & $\mathrm{I} \pm 0.5$ & $0.8 \pm 0.5$ & $0.9 \pm 0.3$ & 0.200 \\
\hline LDL & $2.0 \pm 0.9$ & $2.3 \pm 1.1$ & $1.9 \pm 0.8$ & $1.9 \pm 1.0$ & 0.495 \\
\hline PT & $15.1 \pm 3.4$ & $15.4 \pm 3.1$ & $15.1 \pm 5$ & $15.5 \pm 3.5$ & 0.579 \\
\hline APTT & $41.2 \pm 15.6$ & $42.2 \pm 19.8$ & $39.9 \pm 9.6$ & $42.1 \pm 17.9$ & 0.221 \\
\hline Ferritin & $1100.8 \pm 1298.3$ & $1184.2 \pm 1627.6$ & $1334.4 \pm 1343.9$ & $1034.6 \pm 1166.2$ & 0.322 \\
\hline $\mathrm{LDH}$ & $540.1 \pm 818.1$ & $655 \pm 1560$ & $524 \pm 244$ & $473 \pm 204$ & 0.270 \\
\hline \multicolumn{6}{|l|}{ Outcomes } \\
\hline Pneumonia & $175(85)$ & $52(73.2)$ & 47 (95.9) & $76(88.4)$ & $0.001 *$ \\
\hline ARDS & $21(10.2)$ & $6(8.5)$ & $7(14.3)$ & $8(9.3)$ & 0.547 \\
\hline Mechanical Ventilation & $58(28.3)$ & I8 (25.4) & $20(4 I .7)$ & $20(23.3)$ & $0.06 \mathrm{I}$ \\
\hline Shock & $15(7.3)$ & $4(5.6)$ & $5(10.2)$ & $6(7)$ & 0.632 \\
\hline Acute Kidney Injury & $57(27.7)$ & $16(22.5)$ & $13(26.5)$ & $28(32.6)$ & 0.369 \\
\hline Heart Failure & $17(8.3)$ & I (I.4) & $6(12.2)$ & $10(11.6)$ & $0.035^{*}$ \\
\hline ICU admission & $119(57.8)$ & $38(53.5)$ & 35 (7I.4) & $46(53.5)$ & 0.085 \\
\hline LOS (day) & $18.9 \pm 15.5$ & $17.5 \pm 16.6$ & $23.6 \pm 16.7$ & $17.9 \pm 14.9$ & 0.193 \\
\hline Death & $58(28.2)$ & $15(2 \mid .1)$ & $16(32.7)$ & $27(31.4)$ & 0.263 \\
\hline
\end{tabular}

Notes: Data are presented as mean \pm standard deviation or number $(\%)$; *Statistically significant.

Abbreviations: SOB, shortness of breath; HgAIC, hemoglobin al c; HDL, high-density lipoprotein cholesterol; LDL, low-density lipoprotein cholesterol; PT, prothrombin time; APTT, activated partial thromboplastin time; LDH, lactic dehydrogenase; ARDS, acute respiratory distress syndrome; LOS, length of stay.

This study also found that males were more affected by COVID-19 than females, and the majority were intermediate and high FRS risk (61.2\% and $77.9 \%$, respectively, $\mathrm{p}=$ 0.017). This coincides with published epidemiological studies which highlighted that males are more likely to be infected with COVID-19 and more susceptible to its complications, including death. ${ }^{21,22,28,29}$
There was no significant difference in the presenting symptoms and the laboratory parameters between different FRS risk categories, including markers of disease severity (LDH, D-Dimer, Ferritin). ${ }^{30}$ The most common clinical symptoms were shortness of breath and fever, followed by cough and diarrhoea, which matches with most of the symptoms reported in the literature. ${ }^{31}$ 
Table 3 Multiple Logistic Regression Analyses of Risk Factors Associated with Framingham Risk Score for COVID-19 Patients

\begin{tabular}{|c|c|c|c|c|c|c|c|c|c|}
\hline \multirow[t]{3}{*}{ Risk Factor Variables } & \multicolumn{9}{|c|}{ Framingham Risk Scoring } \\
\hline & \multicolumn{3}{|c|}{ Low Risk (< 10\%) (ref) } & \multicolumn{3}{|c|}{ Intermediate Risk (10-20\%) } & \multicolumn{3}{|c|}{ High Risk (> 20\%) } \\
\hline & OR & $95 \% \mathrm{Cl}$ & $P$ value & OR & $95 \% \mathrm{Cl}$ & $P$ value & OR & $95 \% \mathrm{Cl}$ & P value \\
\hline Age (yr) & - & - & - & 1.35 & $1.19,1.54$ & $<0.00 I^{*}$ & 1.62 & $1.38,1.90$ & $<0.00 I^{*}$ \\
\hline Male sex (vs female) & - & - & - & 0.06 & $0.01,0.43$ & $0.005^{*}$ & 0.01 & $0.00,0.04$ & $<0.001 *$ \\
\hline Smoker (vs non-smoker) & - & - & - & 5.52 & $0.29,104.99$ & 0.256 & 7.09 & $0.13,396.99$ & 0.340 \\
\hline \multicolumn{10}{|c|}{ Comorbidity present (vs not present) } \\
\hline Hypertension & - & - & - & 5.65 & $1.08,29.33$ & $0.039 *$ & 10.98 & $1.75,68.95$ & $0.011 *$ \\
\hline Diabetes mellitus & - & - & - & 23.02 & $2.43,218.28$ & $0.006 *$ & 210.57 & $18.26,2428.16$ & $<0.001 *$ \\
\hline Ischemic Heart Disease & - & - & - & 0.07 & $0.00,6.17$ & 0.246 & 0.16 & $0.00,15.64$ & 0.430 \\
\hline Chronic Kidney Disease & - & - & - & 2.66 & $0.07,99.90$ & 0.596 & 0.42 & $0.00,21.34$ & 0.668 \\
\hline Chronic lung Disease & - & - & - & 6.99 & $0.59,83.57$ & 0.124 & 14.69 & $0.70,308.08$ & 0.083 \\
\hline Heart Failure & - & - & - & 2.76 & $0.07,98.62$ & 0.578 & 3.75 & $0.08,159.57$ & 0.489 \\
\hline Cerebrovascular accident & - & - & - & 0.31 & $0.01,7.19$ & $0.47 \mid$ & 1.55 & $0.07,31.73$ & 0.777 \\
\hline \multicolumn{10}{|l|}{ Outcomes } \\
\hline Pneumonia & - & - & - & 21.19 & I.4I, 318.65 & $0.027^{*}$ & 13.63 & $0.81,229.50$ & 0.070 \\
\hline ARDS & - & - & - & 2.17 & $0.21,21.99$ & 0.512 & 5.59 & $0.40,78.60$ & 0.202 \\
\hline Mechanical Ventilation & - & - & - & 0.91 & $0.12,7.01$ & 0.663 & 0.45 & $0.04,5.18$ & 0.523 \\
\hline Shock & - & - & - & 0.12 & $0.00,3.14$ & 0.205 & 0.07 & $0.00,2.09$ & 0.124 \\
\hline Acute Kidney Injury & - & - & - & 1.94 & $0.29,12.75$ & 0.491 & 3.16 & $0.35,28.83$ & 0.308 \\
\hline Heart Failure & - & - & - & 12.09 & $0.20,733.84$ & 0.234 & 13.29 & $0.20,886.21$ & 0.227 \\
\hline ICU patients & - & - & - & 0.65 & $0.09,3.38$ & 0.529 & 0.93 & $0.11,7.89$ & 0.951 \\
\hline LOS (day) & & & & 1.06 & $1.01,1.12$ & $0.028 *$ & 1.05 & $0.98,1.11$ & 0.169 \\
\hline Death & & & & 0.45 & $0.05,3.97$ & 0.476 & 0.47 & $0.04,6.29$ & 0.570 \\
\hline
\end{tabular}

Note: *Statistically significant.

Abbreviations: ARDS, acute respiratory distress syndrome; ICU, intensive care unit; LOS, length of stay.

With regards to the outcome of the study group, pneumonia was higher in intermediate and high-risk CVD; similarly, more patients with intermediate and high FRS risk patients developed heart failure $(\mathrm{p}=0.035)$. This points to a higher rate of complications in patients with CVD, as reported previously in the literature. ${ }^{12,32}$

FRS has long been used to estimate the 10-year risks of CVD based on disease risk factors. ${ }^{33}$ It has been validated in many studies, with a higher score indicating more CVD risk factors. In addition, it is widely applied and available as online networking applications. ${ }^{34}$

In the present study, 86 (41.4\%) COVID-19 patients had a high FRS score, suggesting that those with high FRS are more prone to COVID-19. We have also detected a trend toward more cardiorespiratory complications among patients with higher FRS score. This is in agreement with Barry et al, who highlighted the challenges of rapidly detecting and properly isolating patients with
MERS-CoV with underlying congestive heart failure (CHF) and chronic kidney disease (CKD) who present with the unexplained deterioration of their chronic conditions. ${ }^{35}$ Hence, it is increasingly evident that the disease tends to be more prevalent and more severe in patients with CHF or CKD. ${ }^{35,36}$ In addition, there is growing evidence that a significant number of COVID-19 patients develop cardiovascular complications, and these were associated with higher mortality. ${ }^{37}$

One of the limitations of this study is that it is a singlecentre experience with a small sample size, which limited the generalization of the data; thus, future studies with larger sample sizes are now needed to investigate the difference in the outcome, including death among the different FRS categories. Another limitation is that it is retrospective data analysis. Some information, such as socioeconomic characteristics, occupation, and level of education, was difficult to collect. Further study is needed 
to determine the relation of CVD risk factors of COVID19 patients and their socioemotional status. Similarly, the exact medication that every patient was receiving was not collected and compared among FRS groups. This could be important as some previous studies have suggested a relation between metformin and statin, for example, with the outcome. ${ }^{6,38}$

\section{Conclusion}

Patients with CVD are more vulnerable to COVID-19 infection, which might worsen their underlying condition and lead to a poor outcome. FRS can identify COVID-19 patients with high-risk CVD and should be confirmed in a larger sample size and different population. It is highly recommended to consider FRS when triaging COVID-19 patients, with timely recognition of high-risk patients while treating cases with a communicable disease. ${ }^{32}$ Public health authorities need to motivate hospitals and primary care clinics to consider CVD risk factors in risk stratification and treatment decisions for patients with COVID-19. They also need to be more vigilant in controlling CVD risk factors since it not only increases the morbidity of non-communicable diseases, but also predisposes to and worsens the outcome of communicable diseases.

\section{Acknowledgments}

The authors are grateful to the Research Center, College of Business Administration and the Deanship of Scientific Research at the King Saud University for supporting this study. We are also grateful to King Saud University Medical City and all employees of the associations who supported data collection.

\section{Author Contributions}

All authors made substantial contributions to conception and design, acquisition of data, or analysis and interpretation of data; took part in drafting the article or revising it critically for important intellectual content; agreed to submit to the current journal; gave final approval of the version to be published; and agree to be accountable for all aspects of the work.

\section{Funding}

This research was funded by the Deputyship for Research \& Innovation, Ministry of Education, Saudi Arabia, through project number IFKSURP-274.

\section{Disclosure}

The authors declare no conflicts of interest.

\section{References}

1. World Health Organisation. Weekly operational update on COVID-19- Emergency situational updates; 2020.

2. Weqaya-Saudi Center for Disease Control and Prevention. COVID19 daily update of cases. Riyadh SA; 2020.

3. Wu Z, McGoogan JM. Characteristics of and important lessons from the coronavirus disease 2019 (COVID-19) outbreak in China: summary of a report of 72314 cases from the Chinese center for disease control and prevention. JAMA. 2020;323(13):1239-1242. doi:10.1001/jama.2020.2648

4. Garg S, Kim L, Whitaker M. Hospitalization rates and characteristics of patients hospitalized with laboratory-confirmed coronavirus disease 2019-COVID-NET, 14 States, March 1-30, 2020. MMWR Morb Mortal Wkly Rep. 2020;69(15):458. doi:10.15585/mmwr. $\mathrm{mm} 6915 \mathrm{e} 3$

5. Hariyanto TI, Kurniawan A. Dyslipidemia is associated with severe coronavirus disease 2019 (COVID-19) infection. Diabetes Metab Syndr. 2020;14(5):1463-1465. doi:10.1016/j.dsx.2020.07.054

6. Hariyanto TI, Kurniawan A. Metformin use is associated with reduced mortality rate from coronavirus disease 2019 (COVID-19) infection. Obes Med. 2020;19:100290. doi:10.1016/j. obmed.2020.100290

7. Alsofayan YM, Althunayyan SM, Khan AA, Hakawi AM, Assiri AM. Clinical characteristics of COVID-19 in Saudi Arabia: a national retrospective study. $J$ Infect Public Health. 2020;13 (7):920-925. doi:10.1016/j.jiph.2020.05.026

8. Statistics GAo. Household Health Survey; 2018.

9. Conroy RM, Pyörälä K, Fitzgerald A, et al. Estimation of ten-year risk of fatal cardiovascular disease in Europe: the SCORE project. Eur Heart J. 2003;24(11):987-1003. doi:10.1016/S0195-668X(03) 00114-3

10. D'agostino RB, Vasan RS, Pencina MJ, et al. General cardiovascular risk profile for use in primary care. Circulation. 2008;117 (6):743-753. doi:10.1161/CIRCULATIONAHA.107.699579

11. AlQuaiz AM, Siddiqui AR, Kazi A, Batais MA, Al-Hazmi AM. Sedentary lifestyle and Framingham risk scores: a population-based study in Riyadh city, Saudi Arabia. BMC Cardiovasc Disord. 2019;19 (1):88. doi:10.1186/s12872-019-1048-9

12. Yang $\mathrm{X}, \mathrm{Yu} \mathrm{Y}, \mathrm{Xu} \mathrm{J}$, et al. Clinical course and outcomes of critically ill patients with SARS-CoV-2 pneumonia in Wuhan, China: a single-centered, retrospective, observational study. Lancet Respir Med. 2020;8(5):475-481. doi:10.1016/S22132600(20)30079-5

13. Algaissi AA, Alharbi NK, Hassanaine M, Hashem AM. Preparedness and response to COVID-19 in Saudi Arabia: building on MERS experience. $J$ Infect Public Health. 2020;13(6):834-838. doi:10.1016/j.jiph.2020.04.016.

14. Badawi A, Ryoo SG. Prevalence of comorbidities in the Middle East respiratory syndrome coronavirus (MERS-CoV): a systematic review and meta-analysis. Int J Infect Dis. 2016;49:129-133. doi:10.1016/j. ijid.2016.06.015

15. Assiri A, Al-Tawfiq JA, Al-Rabeeah AA, et al. Epidemiological, demographic, and clinical characteristics of 47 cases of Middle East respiratory syndrome coronavirus disease from Saudi Arabia: a descriptive study. Lancet Infect Dis. 2013;13(9):752-761. doi:10.1016/S1473-3099(13)70204-4

16. Alsahafi AJ, Cheng AC. The epidemiology of Middle East respiratory syndrome coronavirus in the Kingdom of Saudi Arabia, 2012-2015. Int $J$ Infect Dis. 2016;45:1-4. doi:10.1016/j. ijid.2016.02.004 
17. McCormack V, Tolhurst-Cleaver S. Acute respiratory distress syndrome. BJA Educ. 2017;17(5):161-165. doi:10.1093/bjaed/ mkx002

18. Force AD, Ranieri VM, Rubenfeld GD, et al. Acute respiratory distress syndrome: the Berlin definition. JAMA. 2012;307 (23):2526-2533. doi:10.1001/jama.2012.5669

19. Mercado MG, Smith DK, Guard E. Acute kidney injury: diagnosis and management. Am Fam Physician. 2019;100(11):687-694.

20. Kurmani S, Squire I. Acute heart failure: definition, classification and epidemiology. Curr Heart Fail Rep. 2017;14(5):385-392. doi:10.1007/s11897-017-0351-y

21. Mauvais-Jarvis F. Aging, male sex, obesity, and metabolic inflammation create the perfect storm for COVID-19. Diabetes. 2020;69 (9):1857-1863. doi:10.2337/dbi19-0023

22. Palaiodimos L, Kokkinidis DG, Li W, et al. Severe obesity, increasing age and male sex are independently associated with worse in-hospital outcomes, and higher in-hospital mortality, in a cohort of patients with COVID-19 in the Bronx, New York. Metabolism. 2020;108:154262. doi:10.1016/j.metabol.2020.154262

23. Shah BR, Hux JE. Quantifying the risk of infectious diseases for people with diabetes. Diabetes Care. 2003;26(2):510-513. doi:10.2337/diacare.26.2.510

24. Erener S. Diabetes, infection risk and COVID-19. Mol Metab. 2020;39:101044. doi:10.1016/j.molmet.2020.101044

25. Hodgson K, Morris J, Bridson T, Govan B, Rush C, Ketheesan N. Immunological mechanisms contributing to the double burden of diabetes and intracellular bacterial infections. Immunology. 2015;144(2):171-185. doi:10.1111/imm.12394

26. Huang I, Lim MA, Pranata R. Diabetes mellitus is associated with increased mortality and severity of disease in COVID-19 pneumoniaa systematic review, meta-analysis, and meta-regression. Diabetes Metab Syndr. 2020;14(4):395-403. doi:10.1016/j.dsx.2020.04.018

27. Yang J, Tian C, Chen Y, Zhu C, Chi H, Li J. Obesity aggravates COVID-19: an updated systematic review and meta-analysis. J Med Virol. 2020.

28. Jin J-M, Bai $\mathrm{P}, \mathrm{He} \mathrm{W}$, et al. Gender differences in patients with COVID-19: focus on severity and mortality. Front Public Health. 2020;8:152. doi:10.3389/fpubh.2020.00152
29. Li X, Xu S, Yu M, et al. Risk factors for severity and mortality in adult COVID-19 inpatients in Wuhan. J Allergy Clin Immunol. 2020;146(1):110-118. doi:10.1016/j.jaci.2020.04.006

30. Hariyanto TI, Valeriani K, Kwenandar F, et al. Inflammatory and hematologic markers as predictors of severe outcomes in COVID-19 infection: a systematic review and meta-analysis. Am J Emerg Med. 2020;41:110-119. doi:10.1016/j.ajem.2020.12.076

31. Koh J, Shah SU, Chua PEY, Gui H, Pang J. Epidemiological and clinical characteristics of cases during the early phase of COVID-19 pandemic: a systematic review and meta-analysis. Front Med. 2020;7:295. doi:10.3389/fmed.2020.00295

32. Momtazmanesh S, Shobeiri P, Hanaei S, Mahmoud-Elsayed H, Dalvi B, Rad EM. Cardiovascular disease in COVID-19: a systematic review and meta-analysis of 10,898 patients and proposal of a triage risk stratification tool. Egypt Heart J. 2020;72(1):1-17. doi:10.1186/s43044-020-00075-z

33. Lloyd-Jones DM, Wilson PW, Larson MG, et al. Framingham risk score and prediction of lifetime risk for coronary heart disease. $\mathrm{Am}$ J Cardiol. 2004;94(1):20-24. doi:10.1016/j.amjcard.2004.03.023

34. Jahangiry L, Farhangi MA, Rezaei F. Framingham risk score for estimation of 10-years of cardiovascular diseases risk in patients with metabolic syndrome. J Health Popul Nutr. 2017;36(1):36. doi:10.1186/s41043-017-0114-0

35. Barry M, Al Amri M, Memish ZA. COVID-19 in the shadows of MERS-CoV in the Kingdom of Saudi Arabia. J Epidemiol Glob Health. 2020;10(1):1-3. doi:10.2991/jegh.k.200218.003

36. Madjid M, Safavi-Naeini P, Solomon SD, Vardeny O. Potential effects of coronaviruses on the cardiovascular system: a review. JAMA Cardiol. 2020;5(7):831. doi:10.1001/jamacardio.2020.1286

37. Kwenandar F, Japar KV, Damay V, et al. Coronavirus disease 2019 and cardiovascular system: a narrative review. Int J Cardiol Heart Vasc. 2020;29:100557. doi:10.1016/j.ijcha.2020.100557

38. Hariyanto TI, Kurniawan A. Statin therapy did not improve the in-hospital outcome of coronavirus disease 2019 (COVID-19) infection. Diabetes Metab Syndr. 2020;14(6):1613-1615. doi:10.1016/j.dsx.2020.08.023
Vascular Health and Risk Management

\section{Publish your work in this journal}

Vascular Health and Risk Management is an international, peerreviewed journal of therapeutics and risk management, focusing on concise rapid reporting of clinical studies on the processes involved in the maintenance of vascular health; the monitoring, prevention and treatment of vascular disease and its sequelae; and the involvement of metabolic disorders, particularly diabetes. This journal is indexed on PubMed Central and MedLine. The manuscript management system is completely online and includes a very quick and fair peerreview system, which is all easy to use. Visit http://www.dovepress. com/testimonials.php to read real quotes from published authors. 